Journal of Mathematics and Informatics

Vol. 17, 2019, 91-95

ISSN: 2349-0632 (P), 2349-0640 (online)

Published 19 August 2019

www.researchmathsci.org

DOI: http://dx.doi.org/10.22457/jmi.152av17a8

\section{Journal of}

Mathematics and

Informatics

\title{
The Analysis of Audience Participation on Game Video
}

\author{
Chong-li Wang ${ }^{1}$, Hong Chen ${ }^{2}$, Chun-xia Wang ${ }^{3}$ and Jing Liu ${ }^{4}$ \\ ${ }^{1}$ School of Economics and Management \\ Chongqing University of Posts and Telecommunications \\ Chongqing - 400065, Chongqing, China. E-mail: 1763256864@qq.com \\ ${ }^{2}$ School of Economics and Management \\ Chongqing University of Posts and Telecommunications \\ Chongqing - 400065, Chongqing, China. E-mail: 1159878308@qq.com \\ ${ }^{3}$ School of Economics and Management \\ Chongqing University of Posts and Telecommunications \\ Chongqing-400065, Chongqing, China. E-mail: 1722507936@qq.com \\ ${ }^{4}$ Information and Library Center \\ Chongqing Medical and Pharmaceutical College \\ Chongqing - 401331, Chongqing, China. E-mail: 717139038@qq.com \\ ${ }^{4}$ Corresponding author
}

Received 27 July 2019; accepted 15 August 2019

\begin{abstract}
With the advent of the Internet era, online video has developed rapidly, and the game online video has become one of the most popular network video. By crawler technology, this paper obtained 2,272 data related to audience participation (View, Barrage, Thumb up, Reward and Collect) from the Bilibili video platform. Then, based on Multiple Linear Regression analysis, we explore the influence of four participation indexes of game video audience on collection amount. The research found that view amount, barrage amount, thumb up amount and reward amount of game video have a positive impact on collection amount. In these four indicators, the thumb up has the biggest impact on the collection.
\end{abstract}

Keywords: Game online video; Audience participation; Multiple Linear Regression

AMS Mathematics Subject Classification (2010): 62J05

\section{Introduction}

With the rapid development of Internet technology, many network video platforms have emerged, including youku, tencent, iQIYI, bilibili and so on. By December 2018, the number of Chinese online video (including short video) users has reached 725 million, accounting for $87.5 \%$ of the total Internet users [1]. Among them, game online video (hereinafter referred to as game video) is one of the most popular online video [2]. On the video platforms, audiences can watch videos on online or after download without any limit on playing times and playing time [3]. The viewers also can collect game video, thumb up game video, send barrage to Interact with other users, or reward their favorite UP Lord or online video. 


\section{Chong-li Wang, Hong Chen, Chun-xia Wang and Jing Liu}

The existing research on online video mainly focuses on the influencing factors of audience paying behavior, sending barrages'behavior, watching behavior and so on. Based on the time scale, Wang studied four different indexes of the user engagement -the number of watching movies, the completion rate of watching video, the frequency and interval of visiting [3]. Hu and Yu summarized five behavioral patterns of users in online video platforms (download type, member type, mass type, elite type and fan group type) [4]. Ma explored the influencing factors of audience paying behavior, including perceived usefulness, entertainment, perceived cost and perceived risk [5].

This paper uses web crawler technology to obtain 2272 data related to game video on the bilibili platform. The statistical method of Multiple Linear Regression was used to explore the quantitative change relationship between the indexes of game video user's participation behavior (collection amount and view amount, thumb up amount, reward amount, attention amount and barrage number).

\section{Research hypothesis}

The view amount, thumb up number and collection amount are important indicators to measure whether the game video is popular. Huang found that the proportion of Chinese players watching video content is the first in the world, and the proportion of female esports video audience is the highest in the world [6]. Zhou found that most users use video for entertainment, then the most interactive way for viewers is thumb up when watching the online video [7]. Generally speaking, as a rational person, the higher the audiences' preference for the game video, the more they will watch the video and thumb up, and the higher the corresponding collection. Therefore, this paper makes the following assumptions:

Hypothesis 1: The view amount has a positive impact on collection amount.

Hypothesis 2: The thumb up amount has a positive impact on collection amount.

Content payment has gradually increased in the online video revenue structure. Zhou Yuhua's research found that $50.3 \%$ of users had a gift or money reward on the live video platform. Zhu et al. analyzed the relevant data of the DouYu live broadcast platform and found that there was a positive correlation between the number of viewers and the number and amount of rewards [8]. Moreover, the longer the audience watches, the higher their willingness to reward [9]. This paper speculates that the length of the viewing time represents the level of preference, so the willingness to reward also indicates the viewers' appreciation for the online video, and the audiences who are more willing to reward prefer to reward the videos collected before. Therefore, this paper makes the following assumptions:

Hypothesis 3: The reward amount has a positive impact on collection amount.

Barrage is a real-time comment feature that floats above the video. The unique arrangement of barrage screens enables the barrage commenting on the same video topic to be displayed on the screen at the same time, creating a warm atmosphere of real-time interaction and national discussion [10]. Liu and Wang found that the same screen density and speed of the barrage have an impact on the user's viewing experience [11]. In addition, Jin found that the higher the informational motivation of the audience, the higher the level of participation in the use of the barrage video [12], which led to more 
The Analysis of Audience Participation on Game Video

collection of useful videos to meet their information needs. Therefore, this paper makes the following assumptions:

Hypothesis 4: The barrage amount has a positive impact on collection amount.

\section{Data analysis}

\subsection{Research sample selection}

The bilibili is a well-known video barrage website in China with many partitions, like Music, dance, games, technology, life. $70 \%$ of the content comes from user-made or original video, and currently there are more than 1 million active video creators (UP masters) on the bilibili platform [13]. Therefore, the video website has certain representativeness. More important, it is convenient for us to directly collect the game video information of audience participation, such as view amount, barrage amount.

This research uses web crawler technology to crawl 2400 pieces online video data about game on the bilibili. By deleting 128 duplicate and incomplete data, we collect 2272 pieces of valid data including collection amount, view amount, barrage amount, thumb up amount and reward amount.

\subsection{Descriptive statistics of variables}

Through the collection of 2272 game video data, the average playback volume of the game video was 0.254 million times, and the single-player game spoofed video playback volume reached the highest, 4.366 million times. A video explaining the tenth anniversary of a single-player adventure game occupies the top of the collection, thumb up amount and reward amount, followed by $0.180,0.393$ and 1.428 million coins. The most barrage number of video game reaches up to 1.029 million, which is an e-sports class video.

In addition, the descriptive statistics for obtaining variables is shown in Table 1. The descriptive statistical table contains the maximum value, minimum value, mean value, standard deviation, variance of five variables (view amount, barrage amount, thumb up amount, reward amount and collection amount).

Table 1: Descriptive Statistics

\begin{tabular}{cccccc}
\hline & Minimum & Maximum & Mean & $\begin{array}{c}\text { Std. } \\
\text { Deviation }\end{array}$ & Variance \\
\hline view & 4 & 4366000 & 254129.437 & 500179.624 & 250179656100.000 \\
barrage & 0 & 1029000 & 6217.647 & 32735.480 & 1071611643.000 \\
thumb up & 1 & 393000 & 7612.628 & 21072.651 & 444056619.100 \\
reward & 1 & 1428000 & 8150.253 & 37960.109 & 1440969850.000 \\
collection & 1 & 180000 & 3934.598 & 10985.664 & 120684824.300 \\
\hline
\end{tabular}

\subsection{Establishment of multiple linear regression models}

In this study, view amount, barrage amount, thumb up amount and reward amount are used as input variables in the model, and the collection amount is used as the dependent variable. Using spss24.0 software, this study establishes a Multiple Linear Regression 
Chong-li Wang, Hong Chen, Chun-xia Wang and Jing Liu

model to test hypothesis with the "enter" method. We get the regression model with fitting degree $\mathrm{R}^{2}$ of $87.1 \%$, and the specific results are shown in Table 2 .

Table 2: Least squares estimation results of regression coefficients

\begin{tabular}{|c|c|c|c|c|c|c|c|}
\hline & \multirow{2}{*}{$\begin{array}{c}\text { Unstandardized } \\
\text { Coefficients }\end{array}$} & \multicolumn{2}{|c|}{$\begin{array}{l}\text { Standardized } \\
\text { Coefficients }\end{array}$} & \multirow[t]{2}{*}{$\mathrm{t}$} & \multirow[t]{2}{*}{ Sig. } & \multicolumn{2}{|c|}{$\begin{array}{l}\text { Collinearity } \\
\text { Statistics }\end{array}$} \\
\hline & & Std.Error & Beta & & & Tolerance & VIF \\
\hline (Constant) & 271.356 & 130.369 & & 2.081 & .038 & & \\
\hline thumb up & .224 & .011 & .429 & 20.324 & .000 & .238 & 4.194 \\
\hline view & .009 & .000 & .387 & 21.552 & .000 & .329 & 3.043 \\
\hline reward & .070 & .005 & .242 & 13.158 & .000 & .315 & 3.179 \\
\hline barrage & .035 & .004 & .105 & 8.849 & .000 & .747 & 1.338 \\
\hline
\end{tabular}

From Table 2, it can be seen that information such as unstandardized and standardized coefficients, t-test values, and collinearity diagnosis of the respective variables of the model are obtained. The coefficients of thumb up, view, reward and barrage are positive. The standardized coefficients of thumb up are the largest in the four indices.

Finally, both the normalized residuals histogram and the normalized normal p-p diagram show that the residuals of this equation have the trend of normal distribution, indicating that the multiple linear regression model obtained is reasonable.Therefore, the above four assumptions are supported.

\section{Conclusion and discussion}

\subsection{Conclusion}

Based on the multiple linear regression analysis method, this paper analyzes the data of the participation indexes of 2272 viewers crawled on the video website by spss 24.0 software, and get the following conclusions:

(1) four audience participation indexes (view amount, barrage amount, thumb up amount, reward amount) have a positive impact on the collection of video.The more the audience's playback of the game video, the more points of thumb up and reward, and the higher the corresponding video's collection.

(2) In the four participation indexes of game video viewers (view amount, barrage amount, thumb up amount, reward amount), the most influential one is thumb up amount, followed by view amount, reward amount and barrage amount. When the above four user participation indicators change to the same extent, thumb up amount has the greatest impact on the video collection amount, and each additional 1000 points will increase about 200 collections.

\subsection{Research limitations}

This paper uses a simple multiple linear regression method to analyze the audience participation indexes of the game video. The selection of explanatory variables is not sufficient, because only the audience participation indexes displayed on the website page 
The Analysis of Audience Participation on Game Video

is analyzed (view, barrage, thumb up, reward). In the future, online video crawlers can be used to obtain audience participation indexes of other video websites for analysis. It is also possible to investigate game video viewers through questionnaires and analyze their behavior on the game video platform. In addition, this article only analyzes game video of network video, and subsequent research can be extended to the entire network video, and can compare whether the network videos of different contents are different in the audience participation indexes.

Acknowledgment. This work is supported by the Undergraduate Scientific Research Training Program of Chongqing University of Posts and Telecommunications (K2019107).

\section{REFERENCES}

1. China Network Audiovisual Development Research Report in 2019, CPC Central Committee Network Security and Informatization Committee, 2019.

2. F.Bentley, M.Silverman and M.Bica, Exploring online video watching behaviors, Proceedings of the 2019 ACM International Conference on Interactive Experiences for TV and Online Video. ACM, (2019) 108-117.

3. Y.Wang, Research on video vod system user life cycle and video active period, Beijing Jiaotong University, 2018.

4. Y.W.Hu and G.M.Yu, Research on the behavior model of Chinese network video users, Journal of Zhejiang Communication University, 2 (2018) 9-17.

5. J.Y.Ma, Research on the factors affecting the willingness of online video users to pay, Jinan University, 2017.

6. X.Huang, 2018 digital game consumer insight report, import and export manager, (2008) 60-61.

7. Y.H.Zhou, Who is using live video? Composition, behavior and evaluation of online video broadcast users, Journalist, 3 (2017) 52-62.

8. Z.Zhu, Z.Yang and Y.Dai, Understanding the gift-sending interaction on livestreaming video websites, International Conference on Social Computing and Social Media. Springer, Cham, (2017) 274-285.

9. D.Gros, B.Wanner, A.Hackenholt, et al., World of streaming. Motivation and gratification on Twitch, International Conference on Social Computing and Social Media. Springer, Cham, (2017) 44-57.

10. Z.W.Dong, Research on the consumption behavior of post-1995 users' network video based on questionnaire survey, modern audio-visual, (2008)42-48.

11. L.Y.Liu and J.F.Wang, Research on the design of the video viewing experience of the barrage, Industrial Design Research, (2018) 23.

12. W.J.Jin, The influence of the motivation of the barrage video and the influence of motivation on the degree of participation and dependence, Jinan University, 2015.

13. J.J.Dai, Research on information organization optimization of barrage video website - taking bilibili as an example, Library Research and Work, 7 (2019) 23. 